\title{
Using STAR (Select, Teach, Activate and Revisit) Strategy to Increase Vocabulary Mastery of Eighth Grade Students
}

\author{
Supiah $^{1}$, Defia Syntha Defi ${ }^{2}$ \\ ${ }^{1}$ IAIN Syaikh Abdurrahman Siddik Bangka Belitung \\ ${ }^{2}$ IAIN Syaikh Abdurrahman Siddik Bangka Belitung
}

Keywords:

STAR (Select, Teach, Activate and Revisit) strategy

Increase

Vocabulary mastery

\begin{abstract}
The objectives of this study were: (1) to describe the implementation of STAR (Select, Teach, Activate and Revisit) strategy of the eighth grade students of MTs N 1 Bangka Regency (Islamic Public Junior High School) in Bangka Belitung Province and (2) to find out whether there is any significant difference in vocabulary mastery between the students who were taught by using STAR strategy and the students who were taught without STAR strategy. This study was focused on vocabulary mastery. The total number of sample was 64 students. In this study, the researcher used experimental research method with a quasi-experimental design. The result showed that the students' vocabulary mastery significantly increased. It could be seen from the pre-test and post-test mean score. Furthermore, the result of independent sample t-test of students' post-test between experimental group and control group showed that the t-obtained was higher than t-table $(2.547>2.00)$ and the p-output was lower than computation with level significant $0.05(0.014<0.05)$. It means that the alternative hypothesis $(\mathrm{Ha})$ was accepted and the null hypothesis (Ho) was rejected. It could be concluded that STAR strategy was effective to increase students' vocabulary mastery.
\end{abstract}

Correspondence:

Supiah

Email: supiah10@gmail.com

\section{Introduction}

In this study, the problems faced by the eighth grade students was they had less vocabulary knowledge because they rarely practice their vocabulary in the classroom. Furthermore, the students, as EFL learners, were lazy to memorize words. They had lack of motivation to memorize and practice their vocabulary, whereas vocabulary mastery is necessarily needed to enable them to have an effective communication (Indrawati \& Resti, 2020).

As in preliminary observation, the researcher found that some students did not understand the meaning of words. The students still asked the teacher to find the meaning of vocabulary that they do not know. They were also lazy to look up their dictionary.

Furthermore, the researcher also had given a test to measure students' ability. This test consisted of twenty questions which each five questions had different parts of speech such as verbs, nouns, adverbs and adjectives. The result showed that class $C$ and class $E$ got the lowest score. Students of class $C$ got mean score as much 53.33, meanwhile the students of class E got mean score as much 47.12 . There were some indicators which show the weakness of students' vocabulary. The students chose wrong answers because they were lack of knowledge about the meaning of sentences in each question.

The researcher applied the STAR strategy as one of the strategies used to increase students' vocabulary mastery, especially in descriptive text. It also can make the students more enthusiastic in learning English since it may give them higher achievement motivation which is also contributed by the academic achievement the school demands (Husnayaini, 2019). The researcher believed that this strategy could give positive effect to students' vocabulary because of the research findings of some previous studies. The studies by Maranita (Maranita, 2014), Vlasakova (Vlasákova \& Manuhutu, 2018), Snider (Snider, 2011), 
and Zakaria (Zakaria, 2017) proved that STAR strategy significantly affect students' vocabulary and another skill such as writing ability in descriptive text.

Blachowicz \& Fisher stated that the acronym of STAR stands for Select, Teach, Activate and Revisit. the teacher's first task is to select the best word to receive instructional attention. One way to select comprehension words, those words that are essential to the understanding of a selection, is to use story or text structure to analyze the selection.

The second part of the STAR is to teach. It is helpful to think of the teaching to be done before, during and after reading. It is important to make accessible any concept that are essential to understanding what is to be read and that are not well explained by context. A teacher might choose to explain rebel by giving a sentences containing contextual information, asking students to be active in generating some aspects of a definition and asking them to use the word while giving feedback and finishing with a summary or elaborative definition.

Activate is the third instruction model. The students work in group with new words they have learned. During reading, it is useful to 'assign' each new word to a student, a pair or a team.

The last step is revisit. The critical words are used in discussion for comprehension. Because they have been chosen as essential to understanding the text, they will come up naturally in discussion and teacher questioning, writing after reading, and other tasks, ensuring that they are heard, read, written, and used. In addition, students may revisit new words through review, games, writing, and in many other ways.

STAR strategy was suggested for teaching new words directly. Providing explicit and direct instruction can help students increase their vocabularies (Blachowicz, Fisher, \& Watts-Taffe, 2005).

The power of STAR strategy includes encouraging students to explore words, teaching students new vocabulary actively, students can build strategies to learn new words and also motivate students to build their vocabularies (Blachowicz \& Fisher, 2004).

Due to these problems, the researcher focused on helping students to learn new words and increase their vocabulary size through applying STAR strategy as one of the solutions. The STAR strategy was expected to be able to interest students in learning vocabulary. That is why the researcher would like to conduct a research entitled "Using STAR (Select, Teach, Activate and Revisit) Strategy to Increase Vocabulary Mastery of Eighth Grade Students".

Based on the previous explanation, this research was conducted to know the implementation of STAR (Select, Teach, Activate and Revisit) strategy of the eighth grade students of MTs N 1 Bangka, and to find out whether there was any significant difference in vocabulary mastery between the students who were taught by using STAR strategy and those who were taught without STAR strategy.

\section{Method}

This research used quantitative research to find the answers of research questions in this study. Quantitative research stresses the relationship between manipulated (independent) variable and characteristic of the participant (dependent variable) which is randomly selected the participants and manipulating variables (Tavakoli, 2012). Meanwhile, the method used was experimental method. Experimental research is a study that closely attached to a scientific research design. It includes a hypothesis, a variable that can be manipulated, measured, calculated and compared by the researcher. Most importantly, experimental research is completed in a controlled environment. The researcher collects the data and result that can either support or reject the hypothesis. This method of research is referred to a hypothesis testing or deductive research method (Babbie, 1998). The researcher used quasi-experimental design because the participants were not determined randomly and determined one was the experimental group and another one was the control group. Researchers who use this design rely instead on other techniques to control threats to internal validity (Fraenkel, Wallen, \& Hyun, 2011). Furthermore, the population of quasi-experimental design is selected from a specified population. It is not randomly (Martella, Nelson, \& Marchand-Martella, 1999). Quasi-experimental design was nonequivalent group pretest-posttest. The researcher applied STAR strategy in the experimental group and without STAR strategy in the control group.

The population of this study was all the eighth grade students (junior high school) in Bangka province in the academic year 2019/2020 with a total number of 161 students as the population. However, the researcher decided to choose two classes to be the sample by using purposive sampling: one as the experimental group and the other one as the control group. The researcher's considerations in determining the sample were based on: (a) the English teacher suggestion; and (b) the result of preliminary test which showed that the two classes E got the lowest scores in the test. 
The researcher used two kinds of technique for analyzing the data, such as test and observation. The data of test was analyzed by statistical analysis. The researcher used independent sample t-test on SPSS 17, while the data of observation was analyzed by non-statistical analysis. The data observation was described in description table form. The aspects were observed such as students' participation, cooperation and concept. The form of this observation sheet was adopted from Zainal Asril. The formula could be written as follows:

The percentage $=\frac{\text { The number of aspect }}{\text { The total number of students }} \times 100 \%$

The procedures of this study as stated below:

Before implementing the STAR strategy, the researcher gave a pre-test. The kind of text was multiple choices. There were twenty six questions involved ten questions about noun and for each eight questions about adjective and verb. The test related to the meaning, synonym and antonym of words.

During the first meeting up to tenth meeting, the researcher applied STAR strategy.

1) Pre-Activities

The teacher gave lead-in activities. The teacher:

- Asked students if they ever had a pet.

- Elicited names of pet they had.

- Asked about preferences. Which animals did they think the best pets? Why?

2) Whilst Activities

Select:

- The teacher selected the most essential words (approximately 4 to 6 words).

Teach:

- During reading activity, the students discussed each word from selecting process, how the author uses it.

- The students were given multiple choices sheet and discussed possible meanings, synonyms and antonyms of vocabulary word in the selection.

- After reading activity, the teacher and students discussed the words and the teacher checked whether the students understand the words.

Activate:

- The teacher focused on the work that she/he wanted students do to gain understanding.

- The teacher used writing assignment to make sure students use the targeted words. The teacher gave students the opportunity to connect new words with other words they have already known.

Revisit:

- The teacher asked students individually to make a review about the vocabulary they already have.

3) Post-Activities

- The teacher asked students about what the difficulties they got while teaching learning process.

After accomplishing to implement the STAR strategy, the researcher gave a post-test. The kind of text was same with pre-test, which were multiple choices. 


\section{Results and Discussions}

The research was conducted for tenth meeting in a junior high school. Before implementing the strategy, the researcher gave a pre-test. Then, the researcher applied STAR strategy for ten meetings. After applying the STAR, the researcher gave a post-test. It was used to know whether the implementation of STAR strategy was effective or not for increasing students' vocabulary mastery in descriptive text.

The interpretations of this study consisted of two parts; they were (a) the analysis of implementation and observation, (b) the statistical analyses results.

\section{The Analysis of Implementation and Observation}

After accomplishing the implementation and the observation of STAR strategy in this study, the researcher interpreted that the process of teaching and learning vocabulary mastery on descriptive text by using STAR strategy was effective. It was proved by the results of observation which was done during the implementation of STAR strategy.

Based on the result of observation, the researcher found there were significant differences in students' participation, cooperation and concept. In students' participation aspect, the researcher concluded there was a good significant difference. The students were able to participate in discussing the words selection and answer the questions related the meaning and synonym of words. This activity was applied in the second steps without any explanation about the related words.

In the students' cooperation aspect, the researcher concluded there was a good significant difference. The students were able to cooperate in discussing the words selection and answer the multiple choice questions related the meaning and synonym of words. The students asked to discuss in their groups and share their knowledge about the words. They could underline the unknown words.

Then, in the concept aspect, the researcher concluded there was a good significant difference. The most of students were able to be a critical learner where the students asked to discuss and make connections between what they have already learned about the words and applied their new knowledge to answer the vocabulary questions related to definition, synonym and antonym.

Table 1. The result of observation sheet of experimental group

\begin{tabular}{|c|c|c|c|c|c|c|c|c|c|c|c|}
\hline \multirow[b]{2}{*}{ 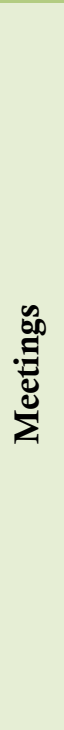 } & \multirow[b]{2}{*}{ 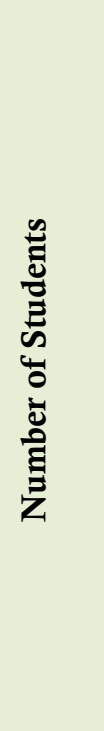 } & \multicolumn{3}{|c|}{ 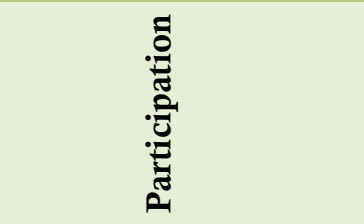 } & \multicolumn{3}{|c|}{ 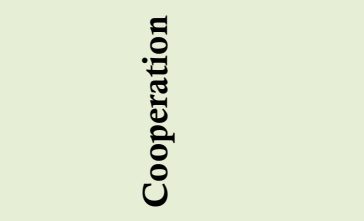 } & \multicolumn{4}{|c|}{ 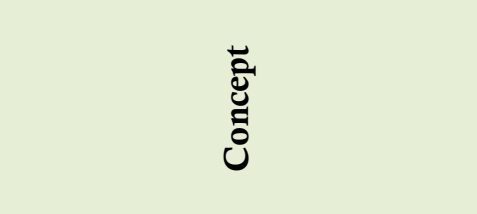 } \\
\hline & & 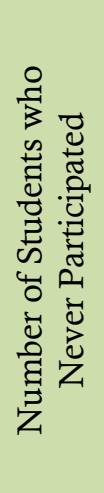 & 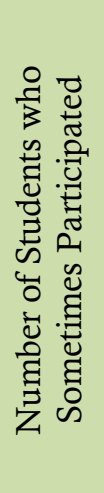 & 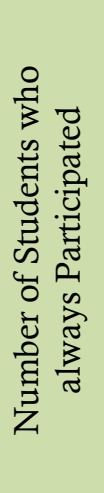 & 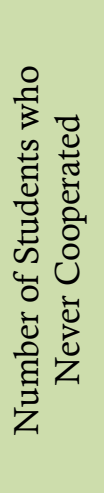 & 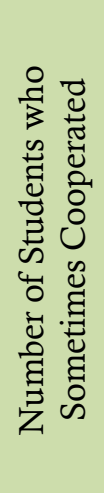 & 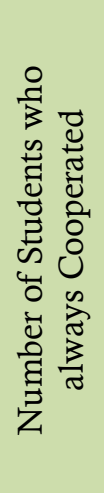 & 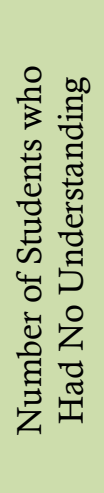 & 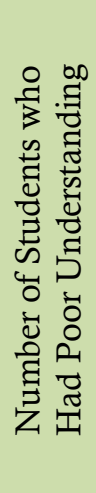 & 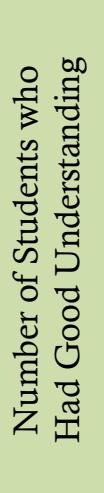 & 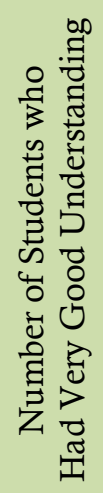 \\
\hline 1 & $88 \%$ & $28 \%$ & $44 \%$ & $16 \%$ & $22 \%$ & $44 \%$ & $22 \%$ & $9 \%$ & $50 \%$ & $0 \%$ & $28 \%$ \\
\hline 2 & $100 \%$ & $31 \%$ & $53 \%$ & $16 \%$ & $19 \%$ & $56 \%$ & $25 \%$ & $0 \%$ & $59 \%$ & $19 \%$ & $22 \%$ \\
\hline 3 & $94 \%$ & $31 \%$ & $47 \%$ & $16 \%$ & $19 \%$ & $50 \%$ & $25 \%$ & $16 \%$ & $41 \%$ & $13 \%$ & $25 \%$ \\
\hline 4 & $94 \%$ & $28 \%$ & $50 \%$ & $16 \%$ & $19 \%$ & $50 \%$ & $25 \%$ & $6 \%$ & $47 \%$ & $38 \%$ & $3 \%$ \\
\hline 5 & $97 \%$ & $19 \%$ & $50 \%$ & $28 \%$ & $6 \%$ & $63 \%$ & $28 \%$ & $3 \%$ & $31 \%$ & $28 \%$ & $34 \%$ \\
\hline 6 & $94 \%$ & $16 \%$ & $50 \%$ & $28 \%$ & $6 \%$ & $59 \%$ & $28 \%$ & $0 \%$ & $19 \%$ & $38 \%$ & $38 \%$ \\
\hline 7 & $97 \%$ & $3 \%$ & $53 \%$ & $41 \%$ & $9 \%$ & $56 \%$ & $31 \%$ & $0 \%$ & $16 \%$ & $25 \%$ & $56 \%$ \\
\hline
\end{tabular}




\begin{tabular}{|c|c|c|c|c|c|c|c|c|c|c|c|}
\hline $\mathbf{8}$ & $94 \%$ & $3 \%$ & $50 \%$ & $41 \%$ & $9 \%$ & $41 \%$ & $44 \%$ & $3 \%$ & $6 \%$ & $6 \%$ & $78 \%$ \\
\hline $\mathbf{9}$ & $97 \%$ & $3 \%$ & $44 \%$ & $50 \%$ & $3 \%$ & $47 \%$ & $47 \%$ & $3 \%$ & $6 \%$ & $6 \%$ & $81 \%$ \\
\hline $\mathbf{1 0}$ & $100 \%$ & $3 \%$ & $31 \%$ & $66 \%$ & $0 \%$ & $31 \%$ & $69 \%$ & $0 \%$ & $9 \%$ & $13 \%$ & $78 \%$ \\
\hline
\end{tabular}

Table 2. The result of observation sheet in control group

\begin{tabular}{|c|c|c|c|c|c|c|c|c|c|c|c|}
\hline \multirow[b]{2}{*}{ 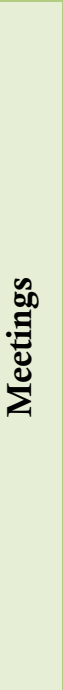 } & \multirow[b]{2}{*}{ 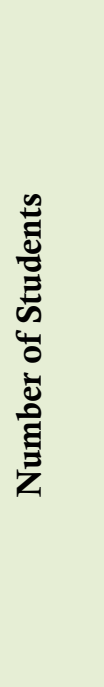 } & \multicolumn{3}{|c|}{ 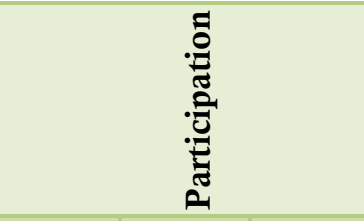 } & \multicolumn{3}{|c|}{ 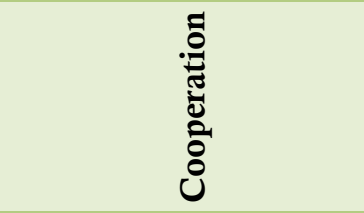 } & \multicolumn{4}{|c|}{ 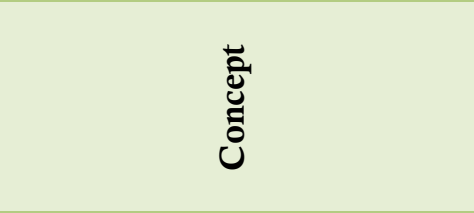 } \\
\hline & & 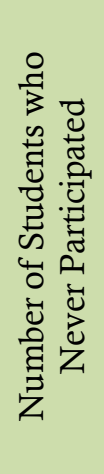 & 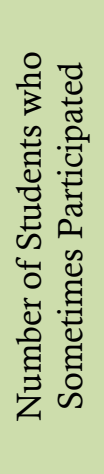 & 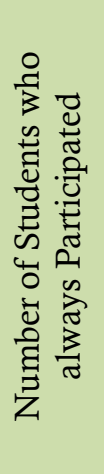 & 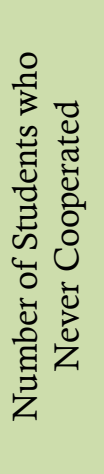 & 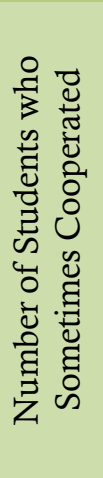 & 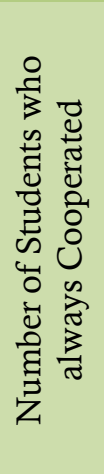 & 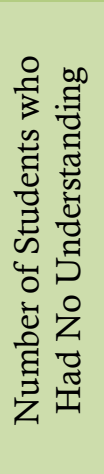 & 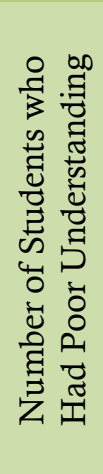 & 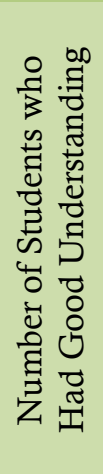 & 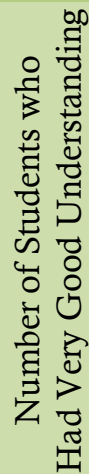 \\
\hline 1 & $97 \%$ & $25 \%$ & $56 \%$ & $16 \%$ & $19 \%$ & $59 \%$ & $19 \%$ & $28 \%$ & $16 \%$ & $16 \%$ & $38 \%$ \\
\hline 2 & $91 \%$ & $19 \%$ & $53 \%$ & $19 \%$ & $13 \%$ & $59 \%$ & $19 \%$ & $25 \%$ & $16 \%$ & $16 \%$ & $34 \%$ \\
\hline 3 & $100 \%$ & $25 \%$ & $63 \%$ & $13 \%$ & $19 \%$ & $53 \%$ & $28 \%$ & $19 \%$ & $34 \%$ & $16 \%$ & $31 \%$ \\
\hline 4 & $94 \%$ & $22 \%$ & $59 \%$ & $13 \%$ & $13 \%$ & $44 \%$ & $38 \%$ & $13 \%$ & $34 \%$ & $16 \%$ & $31 \%$ \\
\hline 5 & $97 \%$ & $22 \%$ & $47 \%$ & $28 \%$ & $19 \%$ & $47 \%$ & $31 \%$ & $0 \%$ & $41 \%$ & $56 \%$ & $0 \%$ \\
\hline 6 & $94 \%$ & $19 \%$ & $34 \%$ & $41 \%$ & $13 \%$ & $50 \%$ & $31 \%$ & $19 \%$ & $13 \%$ & $6 \%$ & $56 \%$ \\
\hline 7 & $97 \%$ & $16 \%$ & $44 \%$ & $38 \%$ & $13 \%$ & $56 \%$ & $28 \%$ & $9 \%$ & $38 \%$ & $3 \%$ & $47 \%$ \\
\hline 8 & $91 \%$ & $6 \%$ & $63 \%$ & $22 \%$ & $6 \%$ & $41 \%$ & $44 \%$ & $6 \%$ & $3 \%$ & $31 \%$ & $50 \%$ \\
\hline 9 & $94 \%$ & $6 \%$ & $56 \%$ & $31 \%$ & $3 \%$ & $50 \%$ & $41 \%$ & $3 \%$ & $6 \%$ & $47 \%$ & $38 \%$ \\
\hline 10 & $97 \%$ & $3 \%$ & $47 \%$ & $47 \%$ & $3 \%$ & $44 \%$ & $50 \%$ & $3 \%$ & $3 \%$ & $3 \%$ & $88 \%$ \\
\hline
\end{tabular}

2. The Statistical Analyses Results

After accomplishing the treatment in teaching vocabulary by using STAR strategy, the researcher concluded that STAR strategy was an effective strategy in increasing students' vocabulary mastery. The researcher interpreted that there was a significant difference between students who were taught by using STAR strategy and the students were taught without using STAR strategy. It was proved by explanation below.

Table 3. The result of pre-test and post-test in experimental and control groups

\begin{tabular}{|c|c|c|c|}
\hline \multirow{2}{*}{ No } & Groups & \multicolumn{2}{|c|}{ Average Score } \\
\cline { 2 - 4 } & $\mathbf{1}$ & Pre-test & Post-test \\
\hline $\mathbf{2}$ & Experimental Group & 51.97 & 75.63 \\
\hline
\end{tabular}


Figure 1. Pretest and posttest score comparisons (experimental group)

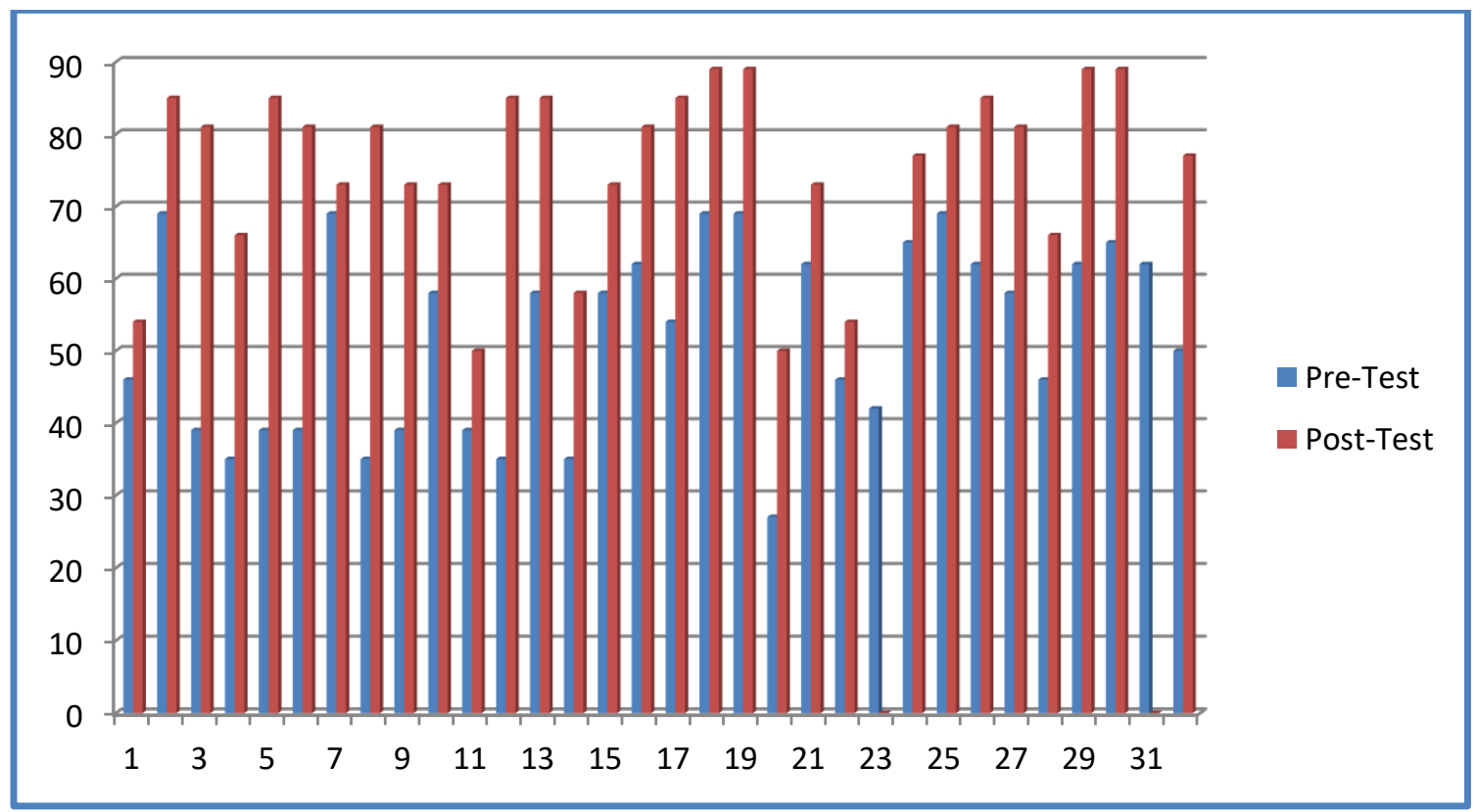

Figure 2. Pretest and posttest score comparisons (control group)

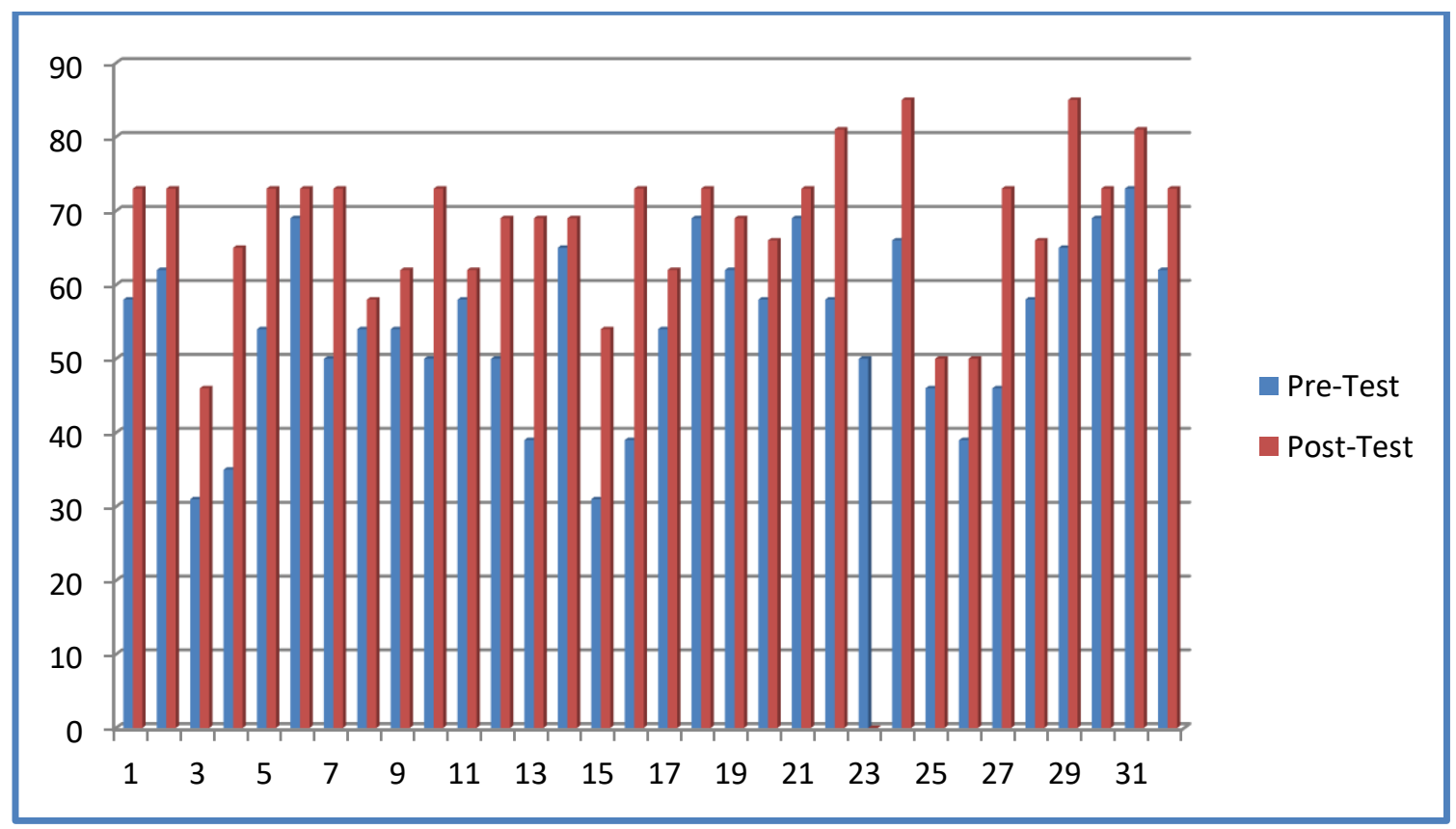


Figure 3. Pretest score comparisons (experimental and control groups)

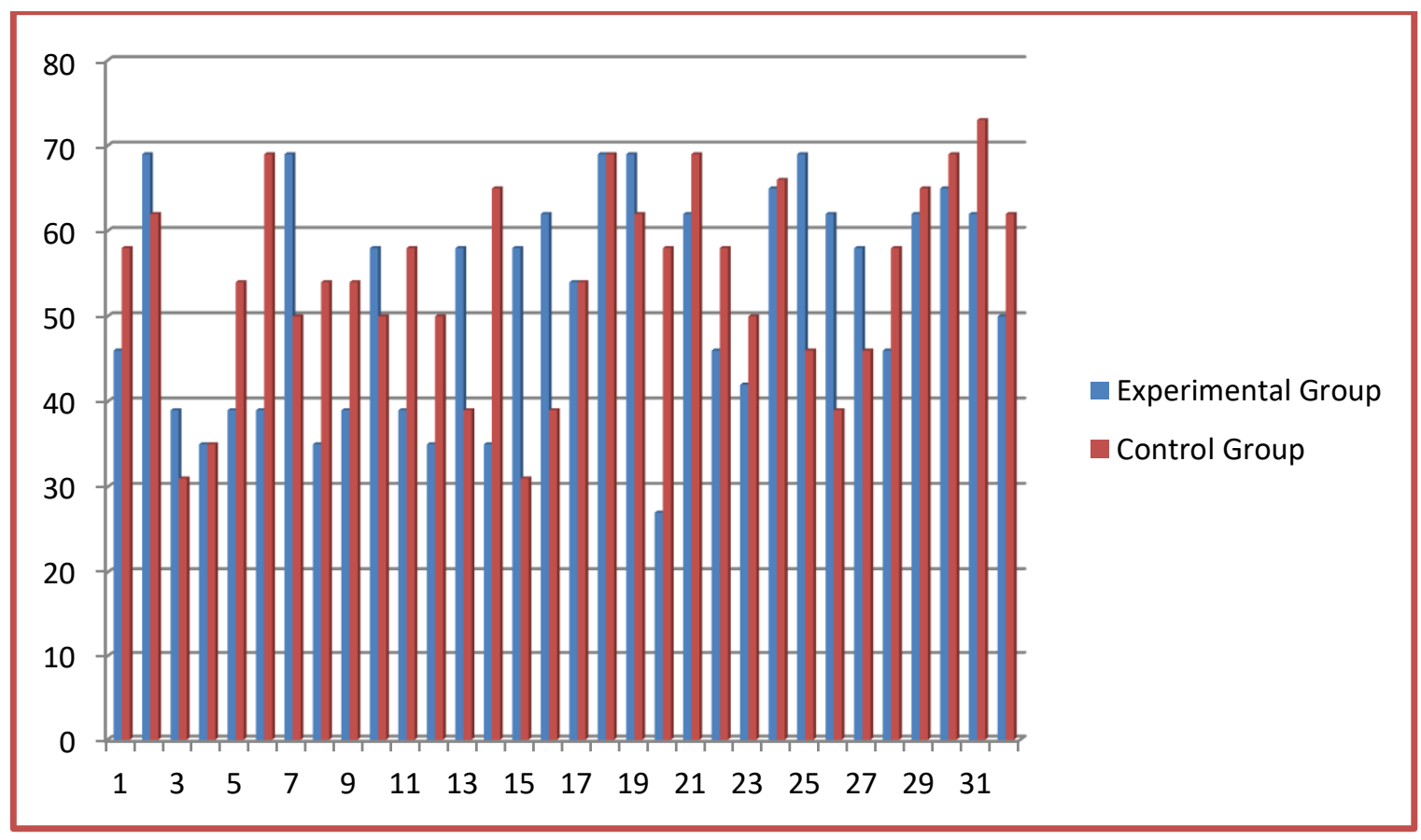

Figure 4. Posttest score comparisons (experimental and control groups)

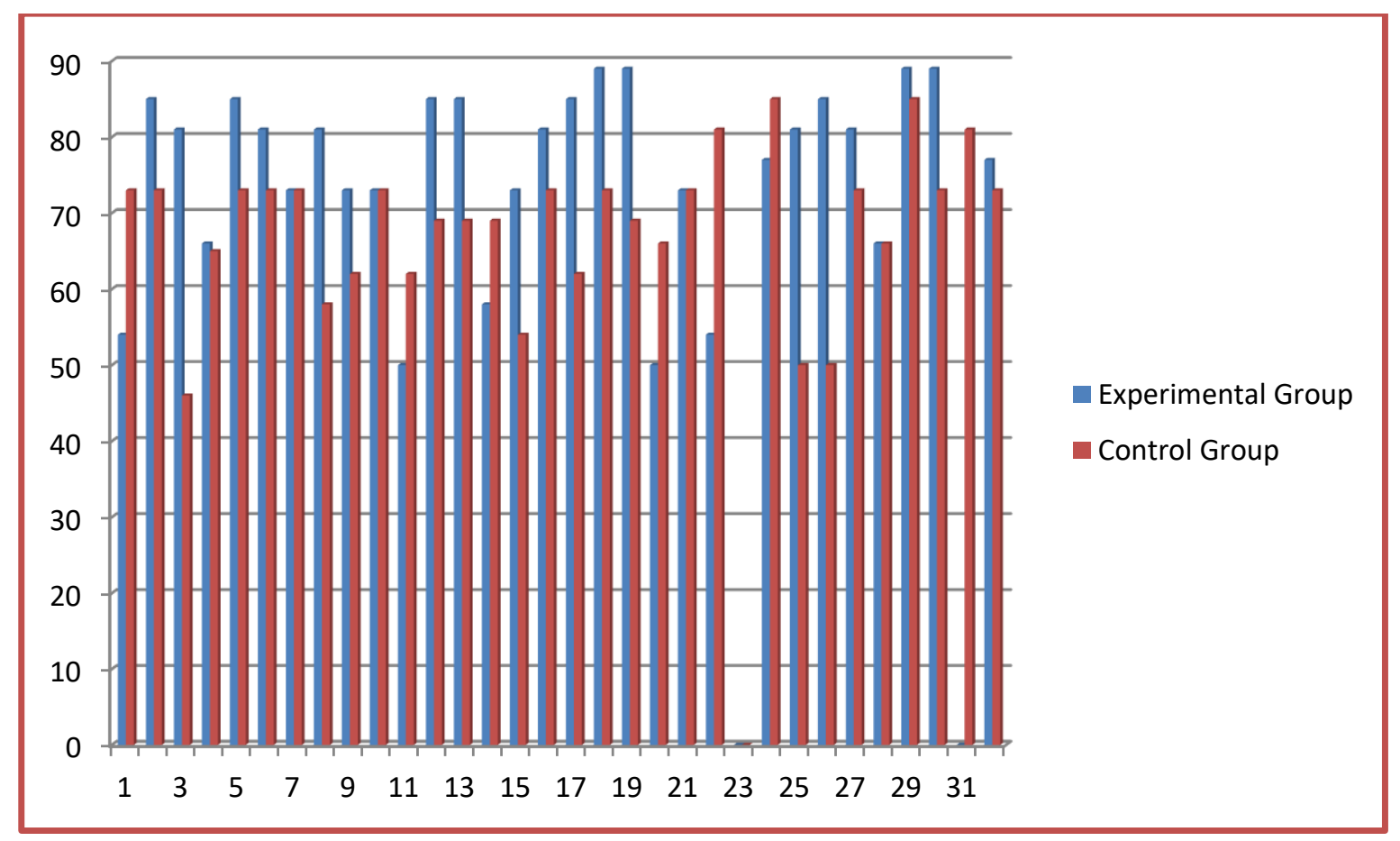

Firstly, based on the students' pre-test and post-test, the results of pre-test and post-test score of experimental group who were taught by using STAR strategy and control group were taught without using STAR strategy were described as follow: (a) the lowest score in the pre-test was 27 and the highest one was 69. Then, the average of students' pre-test score was 51.97. Another, in the post-test, the lowest score was 50 and the highest one was 89 . Then, the average of students' post-test score was 
75.63. Therefore, the researcher could conclude that the all students' score in the experimental group were increased; (b) the lowest score in the pre-test was 31 and the highest one was 73 . The average of students' pre-test score was 54.61. Furthermore, in the post-test, the lowest score was 46 and the highest one was 85. In addition, the average of students' post-test score was 68.55. Therefore, the researcher could conclude that the students' score in the control group were increased.

Table 4. Independent Samples T-test in Post-Test

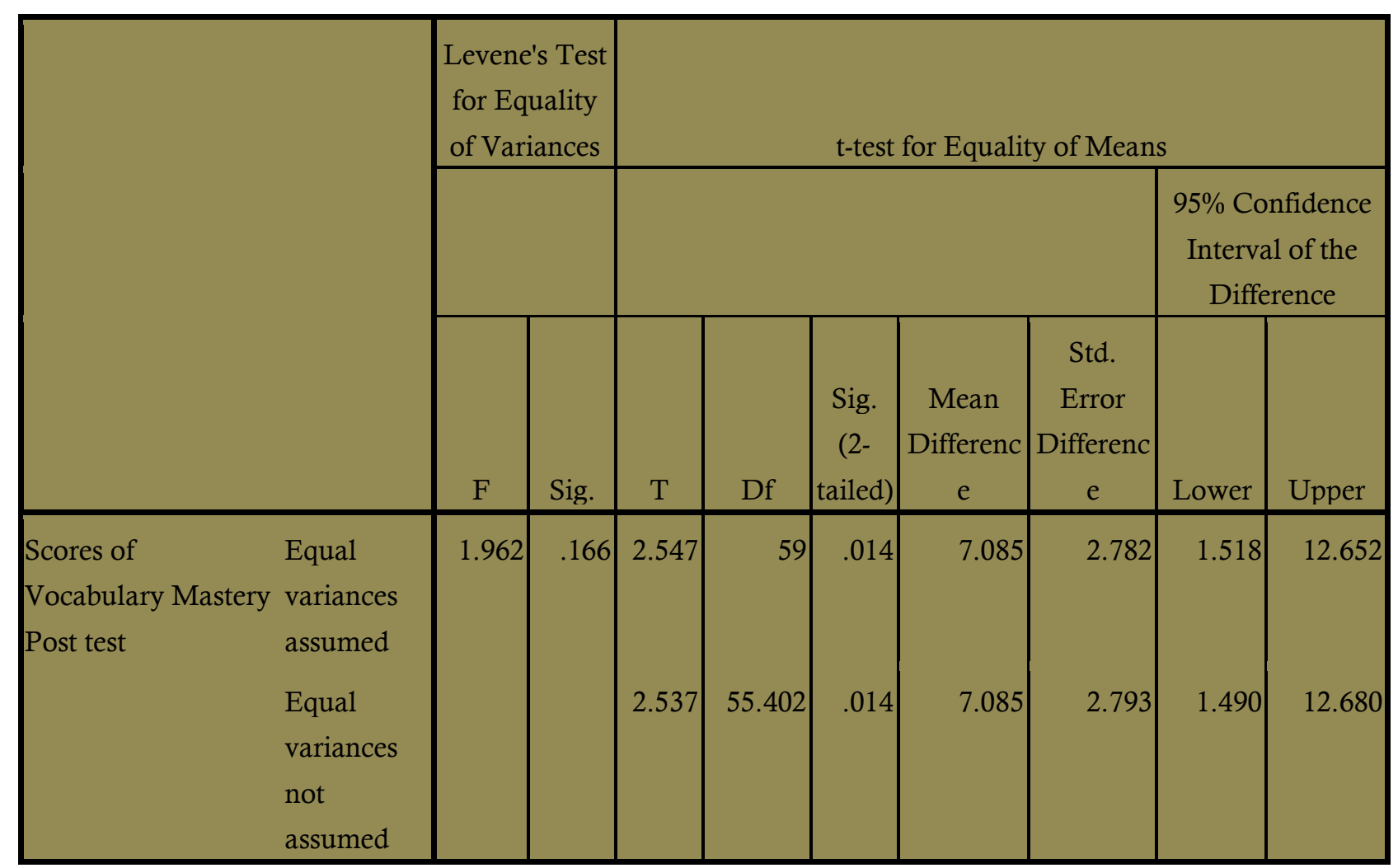

Secondly, based on the independent sample t-test, it was found that the mean difference between posttest in experimental group and control group was 7.085, and standard error was 2.782. Then, significant (2-tailed) was 0.014 , t-obtained was 2.547, critical value of t-table was 2.00 and degree of freedom was 59. Since, the p-output or the significant (2-tailed) was 0.014 , lower than computation with level significant 0.05 and tobtained was 2.547 higher than critical value of t-table 2.00, it could be stated that there was a significant difference in post-test between experimental group and control group. From the description above, the researcher concluded that there was a significant difference between students who were taught by using STAR strategy and the students were taught without using STAR strategy. Therefore, the alternative hypothesis (Ha) was accepted, while the null hypothesis (Ho) was rejected.

These results were supported by some previous studies who stated that there was a significant difference between the students who were taught by using STAR strategy and those who were not. One of the previous studies supported this result which was conducted by Vlasakova and Manuhutu entitled "Applying STAR Strategy to Improve Students' Vocabulary", the findings of this study showed that STAR strategy was effective to improve vocabulary mastery. It could be seen from the result of students' average score. The students' pre-test scores were lower than the post-test. It means that Alternative hypothesis ( $\mathrm{Ha}$ ) could be accepted and Null hypothesis was rejected. In short, there was a significant effect on the students' vocabulary mastery by using STAR strategy. 


\section{Conclusions}

This study was conducted in an Islamic junior high school in Bangka. There were 64 students which consisted of two classes, Experimental Group and Control Group. The aim of this research was to increase the students' vocabulary mastery by using Select, Teach, Activate, and Revisit (STAR) strategy. This study used quantitative data related to the use of STAR strategy in increasing vocabulary mastery of the eight grade. As stated in the discussion, it could be concluded that the use of STAR strategy was effective in increasing the students' vocabulary mastery.

The STAR strategy helped the students learn new words directly. It guided them to discuss and understand the meaning, synonym and antonym of words through direct instruction that could help students answer the questions which were related to the descriptive text easier than before. During the teaching and learning process, the students showed positive responses and enjoyed the implementation of STAR strategy.

Furthermore, there was a significant difference in vocabulary mastery between experimental group and control group. It could be shown from the mean score of the post-test in experimental group (75.63) which was higher than the mean score in control group (68.55). Then, the result of independent sample t-test stated that t-obtained was 2.547 was higher than critical value of t-table 2.00 and the significant (2-tailed) was 0.014 , lower than computation with level significant 0.05 . This result meant that the null hypothesis (Ho) was rejected, while the alternative hypothesis $(\mathrm{Ha})$ was accepted. It could be summed up that there was a significant difference between students who were taught by using STAR strategy and the students were taught without using STAR strategy. After discussing the interpretation of the implementation STAR strategy and the interpretation of statistical analysis result, the researcher concluded that STAR strategy could be applied as an alternative strategy to increase students' vocabulary mastery.

\section{References}

Babbie, E. (1998). The Practice of Social Research 8th Ed Wadsworth Publishing Company. Belmont, CA.

Blachowicz, C. L. Z., \& Fisher, P. (2004). Vocabulary lessons. Educational Leadership, 61(6), 66-69.

Blachowicz, C. L. Z., Fisher, P. J., \& Watts-Taffe, S. (2005). Integrated Vocabulary Instruction: Meeting the Needs of Diverse Learners in Grades K? 5. Learning Point Associates/North Central Regional Educational Laboratory (NCREL).

Fraenkel, J. R., Wallen, N. E., \& Hyun, H. H. (2011). How to design and evaluate research in education. New York: McGraw-Hill Humanities/Social Sciences/Languages.

Husnayaini, I. (2019). Student Self-Concept and Achievement Motivation of High School Students. Tarbawy: Jurnal Pendidikan Islam, 6(2), 113-123.

Indrawati, I., \& Resti, F. (2020). Using Anagram Technique to Develop Students' Vocabulary Mastery to the Seventh Grade Students. SUSTAINABLE: Jurnal Kajian Mutu Pendidikan, 3(2), 86-96.

Maranita, E. (2014). THE EFFECT OF APPLYING SELECT-TEACH-ACTIVATE-REVISIT TECHNIQUE ON STUDENTS VOCABULARY ACHIEVEMENT IN READING. UNIMED.

Martella, R. C., Nelson, J. R., \& Marchand-Martella, N. E. (1999). Research methods: Learning to become a critical research consumer. Allyn \& Bacon.

Tavakoli, H. (2012). A dictionary of research methodology and statistics in applied linguistics. Rahnama press.

Vlasákova, J., \& Manuhutu, N. (2018). Applying STAR Strategy to Improve Students' Vocabulary. ELS Journal on Interdisciplinary Studies in Humanities, 1(2), 210-217.

Zakaria, R. (2017). The Impact of Using Select, Teach, Apply and Revisit (STAR) Model on Students' Writing Ability at MAN 1 Makassar. Universitas Islam Negeri Alauddin Makassar. 